\title{
Molecular cues involved in the regulation of $B$ cell dynamics: assistants of antigen hunting
}

\section{Authors}

Yolanda R. Carrasco* ${ }^{*} \dagger$

\begin{abstract}
Affiliation
*B Cell Dynamics Laboratory, Department of Immunology and Oncology, Centro Nacional de Biotecnología (CNB)-CSIC, Darwin 3, Madrid E-28049, Spain
\end{abstract}

†Corresponding author: Yolanda R. Carrasco, ycarrasco@cnb.csic.es

Running title: Regulation of B cell dynamics

Summary sentence: Review of the molecular signals that govern the initial phase of the B cell response by shaping cell dynamics.

Total $\mathbf{n}^{0}$ of words:

Figures: 2 


\begin{abstract}
Abbreviatures
7 $\alpha, 25-\mathrm{HC}, 7 \alpha, 25$-dihydroxycholesterol; APC, antigen presenting cell; BCR, B cell receptor; Btk, Bruton's tyrosine kinase; cSMAC, central supramolecular activation cluster; DAMP, danger-associated molecular patterns; EBI2, Epstein-Barr virus-induced G-protein coupled receptor 2; ICAM-1, intercellular adhesion molecule-1; IS, immune synapse; LPS, lipopolysaccharides; LFA-1, lymphocyte function-associated antigen-1; MRC, marginal reticular cells; MTOC, microtubule organizing center; PAMP, pathogenassociated molecular patterns; PRR, pattern recognition receptors; pSMAC, peripheral supramolecular activation cluster; $\mathrm{PIP}_{2}$, phosphatidylinositol-4,5-bisphosphate; PIP5KI, phosphatidylinositol-4-phosphate 5-kinase; PID, primary immunodeficiency; SLO, secondary lymphoid organs; S1P, sphingosine-1-phosphate; S1PR, sphingosine-1phosphate receptor; TLR, Toll-like receptors; VCAM-1, vascular cell adhesion molecule1; WASP, Wiskott-Aldrich syndrome protein; WIP, WASP-interacting protein; XLA, Xlinked agammaglobulinemia.
\end{abstract}




\begin{abstract}
The ability of a cell to migrate, adhere and change its morphology is determinant to develop its functions; these capacities reach their maximum relevance in immune cells. For an efficient immune response, immune cells must localize in the right place at the right time; that implies crossing tissue barriers and migrating in the interstitial space of the tissues at high velocities. The dependency on trafficking abilities is even higher for B cells, one of the arms of the adaptive immune system, considering that they must encounter specific antigen for their clonal receptor in the enormous tissue volume of the secondary lymphoid organs (spleen, lymph nodes, Peyer patches). The regulated interplay between cell motililty and cell adhesion allows B cells to reach distinct lymphoid tissues and, within them, to explore the stromal cell networks where antigen might be exposed. In this meeting-invited review, I summarize the current knowledge on the molecular cues and mechanisms that shapes B cell dynamics at the initial phase of the humoral immune response, including homeostatic chemoatractants and innate/inflamatory stimuli. I also revised the $\mathrm{B}$ cell behaviour alterations caused by BCR recognition of antigen and the molecular mechanisms involved.
\end{abstract}

Key words: B cells, chemoattractants, innate signals, motility, antigen, immune synapse. 


\section{Introduction}

B lymphocytes are responsible for the neutralization and elimination of pathogens through the production of antibodies with high specificity for the antigens present on those microbes. The prompt onset of the humoral immune response is crucial to fight against the invaders, and depends on the B cell ability to search and detect antigen at the secondary lymphoid organs (SLO). The knowledge of "how, where and when" B cells find antigen in vivo experienced a great revolution in the last decade due to the development of new experimental models together with the application of multiphoton microscopy [1-3]. The visualization of the B cell immune response in situ and in real time revealed the intrinsic complexity of the process.

B cells are able to travel across tissue barriers and move through the interstitial space in response to external signals $[4,5]$. Continuous migration allows them to seek for pathogen-derived antigens at SLO . The recognition of specific antigen halts motile B cells and leads to the formation of the immune synapse with the antigen-presenting cell (APC) $[1,2]$; this long-lasting cell-to-cell interaction is critical for B cell activation [68]. B cells are also exposed to a variety of non-cognate signals such as innate/inflammatory stimuli that might modify cell motility/adhesion abilities and cell localization. B cell dynamics plasticity is thus intrinsic to B cell function and crucial for adaptive immune protection. This review focuses in the initial phase of the humoral immune response, particularly in the molecular cues that assist naïve B cells to search for antigen (chemoattractants, innate stimuli), as well as in the molecular mechanisms underlying the changes in B cell dynamics caused by BCR recognition of antigen. The processes referred as "B cell dynamics" in here include B cell motility and chemotaxis, cell adhesion, immune synapse formation, in vivo trafficking and tissue localization. 


\section{Steady-state B cell dynamics}

B cells search continuously for antigen at the SLO, where they are organized in structures called follicles and migrate guided by the stromal cell network $[5,9]$. They move with $6 \mu \mathrm{m} / \mathrm{min}$ mean velocity and by random walk to efficiently explore the whole follicular volume $[4,10]$. B cells use an amoeboid type of movement that allows fast migration, lacks strong adhesions with the substrate and keeps the integrity of the tissue where the cells move; amoeboid motility confers high ability for scanning and extracellular signal integration [11]. CXCL13 promotes B cell motility at the follicles signalling through its receptor CXCR5, expressed at the B cell surface. This chemokine is produced mainly at the network of follicular stromal cells, including marginal reticular cells (MRC) in the subcapsular region and follicular dendritic cells in the center, creating a chemokine gradient that drives $\mathrm{B}$ cell location at the follicles $[5,12]$. CXCL13 accumulates in collagen fibers-rich zones and in association with glycosaminoglycan at the surface of stromal cells $[13,14]$, where integrin ligands (ICAM-1, VCAM-1) are present. The combination of surface-bound CXCL13 an integrin ligands might promote haptokinetic (surface-bound chemokine, adhesion assisted) B cell motility, which assists B cell scaning of the stromal cell surface.

Another pair of chemoattractant/chemokine receptor involved in B cell migration and location within the follicle is the lipid $7 \alpha, 25$-dihydroxycholesterol $(7 \alpha, 25-\mathrm{HC})$ and its receptor EBI2 (also known as GPR183). EBI2 is expressed at the surface of all mature B cells, and its level increases within hours after antigen stimulation [15, 16]. EBI2 drives B cells towards the outer follicle and interfollicular regions of SLO. Its ligand 7 $\alpha, 25-\mathrm{HC}$, identified in 2011, is a hydroxylated form of cholesterol [17, 18]. The enzymes responsible of $7 \alpha, 25-\mathrm{HC}$ generation are highly expressed in stromal cells of interfollicular and outer follicular areas of lymphoid tissues, while their levels are lower in the central 
follicular region [19]. The enzymes are also present in the T cell zone, but together with another enzyme that modifies $7 \alpha, 25-\mathrm{HC}$ into a metabolite that does not bind EBI2 [19]. That defined enzyme expression compartimentalization might control $7 \alpha, 25-\mathrm{HC}$ gradients in steady state. The importance of EBI2 as well as of CXCR5 in assiting B cell antigen encounter is consistent with the impaired antibody responses observed in mice lacking one of them $[16,20]$.

B cell exit from lymphoid organs is mainly regulated by another lipid, the lysophospholipid sphingosine-1-phosphate (S1P), and its receptor S1P-receptor-1 (S1PR1). S1P is synthesized by most cell types and it is abundant in plasma $(\sim 1 \mu \mathrm{M})$ and lymph $(\sim 0.1 \mu \mathrm{M})$ fluids, being carried by high density lipoprotein-associated apolipoprotein M and by albumen [21, 22]. Red blood cells, blood and endothelial cells are important S1P producers [23-25]. S1P half-life within interstitial fluids seems to be short, being its degrading enzymes associated to cell membranes. Then, a S1P gradient is established between lymphoid tissue (parenchyma, S1P concentration near nanomolar range) and lymphatic sinusses and vessels (S1P concentration in the micromolar range) that regulates the B cell egress [26-29]. S1PR1 expression can be detected at the surface of B cells isolated from lymphoid tissues but not in those obtained from blood, due to its notable sensitivity to ligand-induced downregulation [30, 31].

Local ligand production and/or accumulation within the follicle might promote homologous desensitization of the respective GPCR. This allows cyclical responsiveness of the receptors (CXCR5, EBI2, S1PR1) and thus B cell exploration of both the periphery and the center of the lymphoid follicle. In addition, heterologous desensitization mechanisms regulate GPCR function; EBI2 heterodimerization with CXCR5 at the B cell surface, in absence of 7 $\alpha, 25-\mathrm{HC}$, dampens CXCL13-mediated responses [32]. 


\section{Modulation of $B$ cell dynamics by antigen recognition}

BCR encounter of antigen triggers B cell activation; while the BCR can bind soluble and membrane-bound antigens, the latter are more efficiently recognized in vivo and more effective in promoting B cell activation (reviewed in [33]). BCR recognition of membrane-bound antigen presented at the surface of the follicular stromal cell network leads B cells to adhere firmly to the APC and form the immune synapse (IS) $[1,2]$. Antigen is gathered and accumulated with the BCR in a central cluster (central supramolecular activation cluster, cSMAC), surrounded by a peripheral domain enriched in the integrin LFA-1 and its ligand ICAM-1 (peripheral SMAC, pSMAC) [34]. The IS has important roles in several aspects of the B cell activation process $[6,7,34]$. In vivo data suggests that $\mathrm{B}$ cells experience several rounds of stop/IS in alternation with go/motile stages to reach full activation, exit the follicle and look for T cell help [1]. Regulation of B cell dynamics thus becomes critical for shaping antigen encounter and subsequent B cell activation. The interplay between BCR (stop/synapse) and CXCR5 (go/motile) signals has a key role in regulating B cell behaviour. In vitro studies showed that BCR signalling strength modifies CXCL13-mediated B cell migration, halting motile B cells above an antigen threshold [35]. In addition, CXCR5 signalling boosts BCRtriggered B cell activation by shaping B cell dynamics in at least two ways: it assists antigen gathering at the IS by promoting membrane ruffling and LFA-1-mediated adhesion and, in conditions of suboptimal antigen abundance, not enough to drive IS formation, CXCR5 signalling promotes the establishment of a LFA-1-supported migratory junction (named kinapse) that allows antigen encounter and BCR signalling integration while B cells are migrating [35].

Several reports gave insights into the molecular mechanisms used by CXCR5 and BCR to coordinate LFA-1 function and adhesion-site dynamics. Chemokine receptor and 
BCR signalling activate LFA-1 by modulating integrin affinity (conformational change) and avidity (spatial distribution and clustering) for ICAM-1 [36, 37]. BCR-triggered IS formation needs of robust actin polymerization and cytoskeletal remodeling for the assembly of an F-actin-rich ring at the pSMAC. The signaling molecules Lyn, Syk, PI3K, Vav proteins, Rac and Rap GTPases and the Wiskott-Aldrich syndrome protein and its interacting protein (WASP/WIP) axis participate in the BCR-driven cytoskeletal rearrangements and LFA-1 activation [38-42]. Syk activation at the IS promotes the translocation of the scaffold protein vinculin from the cytosol to the pSMAC, where it stabilizes integrin clustering and strengthens B cell adhesion [43]. By binding to actin and talin, vinculin links the cortical actin cytoskeleton with adhesion sites at the plasma membrane; it regulates adhesion dynamics and transmission of mechanical forces [44, 45]. Lack of vinculin at the IS impairs appropriate pSMAC assembly, enabling B cells to move in response to CXCL13 whereas displacing the antigen cluster to the uropod [43]. Vinculin recruitment follows an early wave of phosphatidylinositol 4,5-bisphosphate $\left(\mathrm{PIP}_{2}\right)$ production by the phosphatidylinositol-4-phosphate 5-kinase (PIP5KI) [43]; PIP 2 is needed for vinculin activation and recruitment to the plasma membrane [46]. Bruton's tyrosine kinase (Btk) transports PIP5KI from the cytosol to the plasma membrane and thus facilitates $\mathrm{PIP}_{2}$ generation [47]; Btk is recruited by $\mathrm{PI} 3 \mathrm{~K}$-derived $\mathrm{PIP}_{3}$ production [48]. Impaired Btk translocation to the membrane causes B cell inability to trigger IS formation and defects in F-actin polymerization and vinculin recruitment [49]. The $\mathrm{Syk} / \mathrm{Btk} / \mathrm{PIP}_{2} /$ vinculin molecular axis emerges as a major controller of $\mathrm{B}$ cell dynamics.

While the molecular mechanisms involved in halting B cell motility after antigen encounter to form the IS begin to be understood, the cues that drives IS disassembly to regain B cell migration are unknown. As mentioned above, in vivo data indicated several cycles of motility/IS stages interchange within the follicle before exiting towards the $\mathrm{T}$ 
cell zone [1]. One possible mechanism would be the antigen consumption at the APC surface; that would reduce or even stop BCR signaling and allow CXCL13-driven motility, as described for suboptimal antigen abundance or affinity situation [35]. Diminished Syk activation would decrease local $\mathrm{PIP}_{2}$ generation and vinculin recruitment, leading to pSMAC disassembly. Another question that remains opened is the following, if B cells are able to integrate BCR signals while migrating (kinapse stage), why do they stop and form the IS platform on the APC surface? Antigen acquisition and processing need of cell polarization events (MTOC/lysosomes translocation to the IS) and myosin-mediated mechanical force generation $[50,51]$. Motile $\mathrm{B}$ cells might be inefficient to acquire antigen, what compromised its antigen presentation capacity to $\mathrm{T}$ cells and thus the B cell response. Kinapse/synapse stage regulation might be a way to determine B cell tolerance or lack of response versus immunogenic B cell responses.

\section{Modulation of B cell dynamics by non-cognate signals}

During the course of immune responses, B cells can be exposed to inflammatory/innate stimuli such as pathogen-associated molecular patterns (PAMP) and danger-associated molecular patterns (DAMP). Pathogen entrance through infection of or capture by subcapsular sinus macrophages might be an entry route to the follicle; pathogen-derived subproducts and dead-cell-derived ligands due to tissue infection/damage can be also source of innate signals within the follicle. B cells express a plethora of pattern recognition receptors (PRR), such as Toll-like receptor (TLR) family members (reviewed

in [52]). TLR signals are important for the B cell response; they enhance antigenpresentation capacity, cytokine secretion, cell proliferation and differentiation into antibody-secreting cells $[53,54]$. In addition, TLR signals regulate B cell trafficking and localization. TLR stimulation of B1 B cells facilitates their egress from the peritoneal 
cavity [55]; marginal zone B cell location is also affected [56, 57]. TLR4-mediated B cell activation enhances homing to lymph nodes and localization to germinal centres [58].

The effects of innate signals in B cell dynamics and their consequences in antigen recognition and B cell activation are largely unexplored. B cell exposure to the pathogenderived ligand LPS modifies cell dynamics over time [59]. TLR4-signals "primed" B cells for subsequent responses to CXCL13 and CCL21, promoting increased cell polarization, migration and directionality [59]. Increased directionaly relates with Lévy walks type of motility, that improves target (antigen) seeking efficiency [60]. In contrast to the runs-and-pauses that featured random Brownian-like motility, generalized Lévy walks is characterized by straight tracks at fixed speed, promoting large displacements. MyD88-dependent signalling cascade and Rac GTPases were involved in those changes [59]. B cell exposure to lentiviral particles also enhanced migration in response to chemokine gradients or in haptokinesis models [61]. Then, pathogen sensing by innate receptors shapes B cell dynamics; more studies are needed to understand the consequences of that in the $\mathrm{B}$ cell antigen recognition process and in the kinapse/synapse balance. Two recent reports revealed TLR/BCR signalling crosstalk and, in particular, how TLR signalling sensitizes the BCR for antigen encounter by modulating the cortical actin cytoskeleton network $[62,63]$. Another scenario is when the TLR ligand is linked to the antigen, and TLR and BCR signalling happen in the same time-frame. The consequences on synapse formation, assembly or stability that might shape the B cell activation process are still opened to exploration.

B cell priming by TLR ligands sets up a danger situation in which recognition of all kind of antigens (self- and non-self) might be affected. This mechanism could contribute to overcome tolerance to self-antigens in chronic inflammation. Antigen/TLR ligand physical association could help B cells to distinguish dangerous versus inert antigens. 
Nonetheless, self-antigen/TLR7 ligand complexes also break tolerance and promote autoimmune diseases. The exposure time to the TLR ligand in both scenarios (priming and physical association) might be a key point to regulate the beneficious versus the dangerous side of TLR stimulation in B cells.

\section{Relevance of B cell dynamics in pathology: primary immunodeficiency (PID)}

B cell-related PID are a group of orphan diseases $\left(1: 10^{4}-10^{5}\right.$ prevalence) of variable severity, and represent the main group $(\sim 65 \%)$ of PID patients. B cell-PID patients have a compromised immune response against pathogens and develop autoimmune diseases and lymphomas; they are treated with unspecific gamma globulins administered subcutaneously or intravenously $[64,65]$. The clinical studies performed on B cell-PID showed a high heterogeneity, making difficult the diagnosis $[66,67]$. That stresses the necessity of a better understanding of the B cell-PID molecular basis. The progress in sequencing technology allows to identify the responsible gene in many cases; the data showed a major implication of actin cytoskeleton-related genes [68, 69]. Mutations in DOCK8 [7], DOCK2 [70], WASP [71], WIP [72], or RasGRP1 [73] have been found in PID patients. The X-linked agammaglobulinemia (XLA) patients present mutations in Btk [64], also involved in actin cytoskeleton rearrangements and adhesion-site dynamics [49]. Studies performed in mouse models underline the relevance of B cell motility, synapse formation, and tissue localization for the B cell response; actin cytoskeleton remodeling is the driving force of those cellular events. The finding that a high number of PID mutations affect genes related with actin cytoskeleton confirms the relevance of cell dynamics for B cell function also in humans. The design of diagnosis test to evaluate the B cell ability to polarize, move and/or form the IS would help in early PID diagnosis 
and in personalized therapies, adjusting treatments depending on the clinical severity of the PID patient.

\section{Concluding remarks}

B cell dynamics regulation by distinct stimuli emerges as a critical aspect for B cell function at the initial stages of the humoral immune response. Chemoattractans (CXCL13, 7 $\alpha, 25-\mathrm{HC}, \mathrm{S} 1 \mathrm{P})$ assist in B cell motility and tissue localization. Antigens halt B cell migration and promote stable B cell-APC contacts through the IS assembly to facilitate antigen acquisition and processing. Once antigen is consumed at the APC surface, B cells would recover motility and continue searching for more antigen over the follicular stromal cell network. TLR signaling modulates B cell trafficking and localization, and improves the B cell strategy to find antigen (Levy's walk motility). Understanding how changes in cell dynamics shape B cell capacity to encounter antigen and respond to it, will reveal essential aspects of the humoral immune response. This knowledge might have therapeutic use, being interstitial migration and cell localization potential targets for either avoiding pathologic immune responses (autoimmune diseases) or enhancing/boosting inefficient humoral responses (immunodeficiency, vaccines).

\section{Authorship}

Y.R.C. wrote this manuscript.

\section{Acknowledgements}

The author thanks S. Roman-Garcia, S.V. Merino-Cortes and R. Jiménez-Saiz, members of the B cell dynamics laboratory, for critical reading of the manuscript, and to MCIU/AEI/FEDER EU for funding. The publication of this review was supported by a 
grant (RTI2018-101345-B-I00) from the Spanish Ministry of Science, Innovation and Universities (MCIU).

\section{Conflict of Interest Disclosure}

The author declares no conflicts of interest. 


\section{References}

1. Carrasco, Y. R. and Batista, F. D. (2007) B cells acquire particulate antigen in a macrophage-rich area at the boundary between the follicle and the subcapsular sinus of the lymph node. Immunity 27, 160-71.

2. Phan, T. G., Grigorova, I., Okada, T., Cyster, J. G. (2007) Subcapsular encounter and complement-dependent transport of immune complexes by lymph node B cells. Nat Immunol 8, 992-1000.

3. Junt, T., Moseman, E. A., Iannacone, M., Massberg, S., Lang, P. A., Boes, M., Fink, K., Henrickson, S. E., Shayakhmetov, D. M., Di Paolo, N. C., van Rooijen, N., Mempel, T. R., Whelan, S. P., von Andrian, U. H. (2007) Subcapsular sinus macrophages in lymph nodes clear lymph-borne viruses and present them to antiviral B cells. Nature 450, 110-4.

4. Miller, M. J., Wei, S. H., Parker, I., Cahalan, M. D. (2002) Two-photon imaging of lymphocyte motility and antigen response in intact lymph node. Science 296, 1869-73.

5. Bajenoff, M., Egen, J. G., Koo, L. Y., Laugier, J. P., Brau, F., Glaichenhaus, N., Germain, R. N. (2006) Stromal cell networks regulate lymphocyte entry, migration, and territoriality in lymph nodes. Immunity 25, 989-1001.

6. Fleire, S. J., Goldman, J. P., Carrasco, Y. R., Weber, M., Bray, D., Batista, F. D. (2006) B cell ligand discrimination through a spreading and contraction response. Science 312, 738-41.

7. Randall, K. L., Lambe, T., Johnson, A., Treanor, B., Kucharska, E., Domaschenz, H., Whittle, B., Tze, L. E., Enders, A., Crockford, T. L., Bouriez-Jones, T., Alston, D., Cyster, J. G., Lenardo, M. J., Mackay, F., Deenick, E. K., Tangye, S. G., Chan, T. D., Camidge, T., Brink, R., Vinuesa, C. G., Batista, F. D., Cornall, R. J., Goodnow, C. C. (2009) Dock8 mutations cripple B cell immunological synapses, germinal centers and long-lived antibody production. Nat Immunol 10, 1283-91.

8. Burbage, M., Keppler, S. J., Gasparrini, F., Martinez-Martin, N., Gaya, M., Feest, C., Domart, M. C., Brakebusch, C., Collinson, L., Bruckbauer, A., Batista, F. D. (2015) $\mathrm{Cdc} 42$ is a key regulator of $\mathrm{B}$ cell differentiation and is required for antiviral humoral immunity. J Exp Med 212, 53-72.

9. Cyster, J. G. (2010) B cell follicles and antigen encounters of the third kind. Nat Immunol 11, 989-96.

10. Okada, T., Miller, M. J., Parker, I., Krummel, M. F., Neighbors, M., Hartley, S. B., O'Garra, A., Cahalan, M. D., Cyster, J. G. (2005) Antigen-engaged B cells undergo chemotaxis toward the $\mathrm{T}$ zone and form motile conjugates with helper $\mathrm{T}$ cells. PLoS Biol 3, e150.

11. Friedl, P. and Weigelin, B. (2008) Interstitial leukocyte migration and immune function. Nat Immunol 9, 960-9.

12. Allen, C. D. and Cyster, J. G. (2008) Follicular dendritic cell networks of primary follicles and germinal centers: phenotype and function. Semin Immunol 20, 1425.

13. Nolte, M. A., Belien, J. A., Schadee-Eestermans, I., Jansen, W., Unger, W. W., van Rooijen, N., Kraal, G., Mebius, R. E. (2003) A conduit system distributes chemokines and small blood-borne molecules through the splenic white pulp. J Exp Med 198, 505-12.

14. Cyster, J. G., Ansel, K. M., Reif, K., Ekland, E. H., Hyman, P. L., Tang, H. L., Luther, S. A., Ngo, V. N. (2000) Follicular stromal cells and lymphocyte homing to follicles. Immunol Rev 176, 181-93. 
15. Pereira, J. P., Kelly, L. M., Xu, Y., Cyster, J. G. (2009) EBI2 mediates B cell segregation between the outer and centre follicle. Nature 460, 1122-6.

16. Gatto, D., Paus, D., Basten, A., Mackay, C. R., Brink, R. (2009) Guidance of B cells by the orphan $\mathrm{G}$ protein-coupled receptor EBI2 shapes humoral immune responses. Immunity 31, 259-69.

17. Liu, C., Yang, X. V., Wu, J., Kuei, C., Mani, N. S., Zhang, L., Yu, J., Sutton, S. W., Qin, N., Banie, H., Karlsson, L., Sun, S., Lovenberg, T. W. (2011) Oxysterols direct B-cell migration through EBI2. Nature 475, 519-23.

18. Hannedouche, S., Zhang, J., Yi, T., Shen, W., Nguyen, D., Pereira, J. P., Guerini, D., Baumgarten, B. U., Roggo, S., Wen, B., Knochenmuss, R., Noel, S., Gessier, F., Kelly, L. M., Vanek, M., Laurent, S., Preuss, I., Miault, C., Christen, I., Karuna, R., Li, W., Koo, D. I., Suply, T., Schmedt, C., Peters, E. C., Falchetto, R., Katopodis, A., Spanka, C., Roy, M. O., Detheux, M., Chen, Y. A., Schultz, P. G., Cho, C. Y., Seuwen, K., Cyster, J. G., Sailer, A. W. (2011) Oxysterols direct immune cell migration via EBI2. Nature 475, 524-7.

19. Yi, T., Wang, X., Kelly, L. M., An, J., Xu, Y., Sailer, A. W., Gustafsson, J. A., Russell, D. W., Cyster, J. G. (2012) Oxysterol gradient generation by lymphoid stromal cells guides activated B cell movement during humoral responses. Immunity 37, 535-48.

20. Junt, T., Fink, K., Forster, R., Senn, B., Lipp, M., Muramatsu, M., Zinkernagel, R. M., Ludewig, B., Hengartner, H. (2005) CXCR5-dependent seeding of follicular niches by B and Th cells augments antiviral B cell responses. J Immunol 175, 7109-16.

21. Christoffersen, C., Obinata, H., Kumaraswamy, S. B., Galvani, S., Ahnstrom, J., Sevvana, M., Egerer-Sieber, C., Muller, Y. A., Hla, T., Nielsen, L. B., Dahlback, B. (2011) Endothelium-protective sphingosine-1-phosphate provided by HDLassociated apolipoprotein M. Proc Natl Acad Sci U S A 108, 9613-8.

22. Murata, N., Sato, K., Kon, J., Tomura, H., Yanagita, M., Kuwabara, A., Ui, M., Okajima, F. (2000) Interaction of sphingosine 1-phosphate with plasma components, including lipoproteins, regulates the lipid receptor-mediated actions. Biochem J 352 Pt 3, 809-15.

23. Pappu, R., Schwab, S. R., Cornelissen, I., Pereira, J. P., Regard, J. B., Xu, Y., Camerer, E., Zheng, Y. W., Huang, Y., Cyster, J. G., Coughlin, S. R. (2007) Promotion of lymphocyte egress into blood and lymph by distinct sources of sphingosine-1-phosphate. Science 316, 295-8.

24. Pham, T. H., Baluk, P., Xu, Y., Grigorova, I., Bankovich, A. J., Pappu, R., Coughlin, S. R., McDonald, D. M., Schwab, S. R., Cyster, J. G. (2010) Lymphatic endothelial cell sphingosine kinase activity is required for lymphocyte egress and lymphatic patterning. J Exp Med 207, 17-27.

25. Venkataraman, K., Lee, Y. M., Michaud, J., Thangada, S., Ai, Y., Bonkovsky, H. L., Parikh, N. S., Habrukowich, C., Hla, T. (2008) Vascular endothelium as a contributor of plasma sphingosine 1-phosphate. Circ Res 102, 669-76.

26. Grigorova, I. L., Panteleev, M., Cyster, J. G. (2010) Lymph node cortical sinus organization and relationship to lymphocyte egress dynamics and antigen exposure. Proc Natl Acad Sci U S A 107, 20447-52.

27. Grigorova, I. L., Schwab, S. R., Phan, T. G., Pham, T. H., Okada, T., Cyster, J. G. (2009) Cortical sinus probing, S1P1-dependent entry and flow-based capture of egressing T cells. Nat Immunol 10, 58-65.

28. Sinha, R. K., Park, C., Hwang, I. Y., Davis, M. D., Kehrl, J. H. (2009) B lymphocytes exit lymph nodes through cortical lymphatic sinusoids by a 
mechanism independent of sphingosine-1-phosphate-mediated chemotaxis. Immunity 30, 434-46.

29. Cyster, J. G. and Schwab, S. R. (2012) Sphingosine-1-phosphate and lymphocyte egress from lymphoid organs. Annu Rev Immunol 30, 69-94.

30. Lo, C. G., Xu, Y., Proia, R. L., Cyster, J. G. (2005) Cyclical modulation of sphingosine-1-phosphate receptor 1 surface expression during lymphocyte recirculation and relationship to lymphoid organ transit. J Exp Med 201, 291-301.

31. Schwab, S. R., Pereira, J. P., Matloubian, M., Xu, Y., Huang, Y., Cyster, J. G. (2005) Lymphocyte sequestration through S1P lyase inhibition and disruption of S1P gradients. Science 309, 1735-9.

32. Barroso, R., Martinez Munoz, L., Barrondo, S., Vega, B., Holgado, B. L., Lucas, P., Baillo, A., Salles, J., Rodriguez-Frade, J. M., Mellado, M. (2012) EBI2 regulates CXCL13-mediated responses by heterodimerization with CXCR5. FASEB J 26, 4841-54.

33. Heesters, B. A., van der Poel, C. E., Das, A., Carroll, M. C. (2016) Antigen Presentation to B Cells. Trends Immunol 37, 844-854.

34. Carrasco, Y. R., Fleire, S. J., Cameron, T., Dustin, M. L., Batista, F. D. (2004) LFA-1/ICAM-1 interaction lowers the threshold of B cell activation by facilitating B cell adhesion and synapse formation. Immunity 20, 589-99.

35. Saez de Guinoa, J., Barrio, L., Mellado, M., Carrasco, Y. R. (2011) CXCL13/CXCR5 signaling enhances B-cell receptor-triggered B-cell activation by shaping cell dynamics. Blood 118, 1560-1569.

36. Kinashi, T. (2007) Integrin regulation of lymphocyte trafficking: lessons from structural and signaling studies. Adv Immunol 93, 185-227.

37. Batista, F. D., Arana, E., Barral, P., Carrasco, Y. R., Depoil, D., Eckl-Dorna, J., Fleire, S., Howe, K., Vehlow, A., Weber, M., Treanor, B. (2007) The role of integrins and coreceptors in refining thresholds for B-cell responses. Immunol Rev 218, 197-213.

38. Weber, M., Treanor, B., Depoil, D., Shinohara, H., Harwood, N. E., Hikida, M., Kurosaki, T., Batista, F. D. (2008) Phospholipase C-gamma2 and Vav cooperate within signaling microclusters to propagate B cell spreading in response to membrane-bound antigen. J Exp Med 205, 853-68.

39. Arana, E., Vehlow, A., Harwood, N. E., Vigorito, E., Henderson, R., Turner, M., Tybulewicz, V. L., Batista, F. D. (2008) Activation of the small GTPase Rac2 via the $\mathrm{B}$ cell receptor regulates $\mathrm{B}$ cell adhesion and immunological-synapse formation. Immunity 28, 88-99.

40. Lin, K. B., Freeman, S. A., Zabetian, S., Brugger, H., Weber, M., Lei, V., DangLawson, M., Tse, K. W., Santamaria, R., Batista, F. D., Gold, M. R. (2008) The rap GTPases regulate $\mathrm{B}$ cell morphology, immune-synapse formation, and signaling by particulate B cell receptor ligands. Immunity $28,75-87$.

41. Meyer-Bahlburg, A., Becker-Herman, S., Humblet-Baron, S., Khim, S., Weber, M., Bouma, G., Thrasher, A. J., Batista, F. D., Rawlings, D. J. (2008) WiskottAldrich syndrome protein deficiency in B cells results in impaired peripheral homeostasis. Blood 112, 4158-69.

42. Keppler, S. J., Gasparrini, F., Burbage, M., Aggarwal, S., Frederico, B., Geha, R. S., Way, M., Bruckbauer, A., Batista, F. D. (2015) Wiskott-Aldrich Syndrome Interacting Protein Deficiency Uncovers the Role of the Co-receptor CD19 as a Generic Hub for PI3 Kinase Signaling in B Cells. Immunity 43, 660-73. 
43. Saez de Guinoa, J., Barrio, L., Carrasco, Y. R. (2013) Vinculin arrests motile B cells by stabilizing integrin clustering at the immune synapse. J Immunol 191, 2742-51.

44. Humphries, J. D., Wang, P., Streuli, C., Geiger, B., Humphries, M. J., Ballestrem, C. (2007) Vinculin controls focal adhesion formation by direct interactions with talin and actin. J Cell Biol 179, 1043-57.

45. Carisey, A. and Ballestrem, C. (2010) Vinculin, an adapter protein in control of cell adhesion signalling. Eur J Cell Biol 90, 157-63.

46. Bakolitsa, C., Cohen, D. M., Bankston, L. A., Bobkov, A. A., Cadwell, G. W., Jennings, L., Critchley, D. R., Craig, S. W., Liddington, R. C. (2004) Structural basis for vinculin activation at sites of cell adhesion. Nature 430, 583-6.

47. Saito, K., Tolias, K. F., Saci, A., Koon, H. B., Humphries, L. A., Scharenberg, A., Rawlings, D. J., Kinet, J. P., Carpenter, C. L. (2003) BTK regulates PtdIns-4,5P2 synthesis: importance for calcium signaling and PI3K activity. Immunity 19, 669-78.

48. Kurosaki, T. and Hikida, M. (2009) Tyrosine kinases and their substrates in B lymphocytes. Immunol Rev 228, 132-48.

49. Roman-Garcia, S., Merino-Cortes, S. V., Gardeta, S. R., de Bruijn, M. J. W., Hendriks, R. W., Carrasco, Y. R. (2018) Distinct Roles for Bruton's Tyrosine Kinase in B Cell Immune Synapse Formation. Front Immunol 9, 2027.

50. Yuseff, M. I., Reversat, A., Lankar, D., Diaz, J., Fanget, I., Pierobon, P., Randrian, V., Larochette, N., Vascotto, F., Desdouets, C., Jauffred, B., Bellaiche, Y., Gasman, S., Darchen, F., Desnos, C., Lennon-Dumenil, A. M. (2011) Polarized secretion of lysosomes at the $\mathrm{B}$ cell synapse couples antigen extraction to processing and presentation. Immunity 35, 361-74.

51. Natkanski, E., Lee, W. Y., Mistry, B., Casal, A., Molloy, J. E., Tolar, P. (2013) B cells use mechanical energy to discriminate antigen affinities. Science 340, 158790.

52. Buchta, C. M. and Bishop, G. A. (2014) Toll-like receptors and B cells: functions and mechanisms. Immunol Res 59, 12-22.

53. Pasare, C. and Medzhitov, R. (2005) Control of B-cell responses by Toll-like receptors. Nature 438, 364-8.

54. Hou, B., Saudan, P., Ott, G., Wheeler, M. L., Ji, M., Kuzmich, L., Lee, L. M., Coffman, R. L., Bachmann, M. F., DeFranco, A. L. (2011) Selective utilization of Toll-like receptor and MyD88 signaling in B cells for enhancement of the antiviral germinal center response. Immunity 34, 375-84.

55. Ha, S. A., Tsuji, M., Suzuki, K., Meek, B., Yasuda, N., Kaisho, T., Fagarasan, S. (2006) Regulation of B1 cell migration by signals through Toll-like receptors. J Exp Med 203, 2541-50.

56. Rubtsov, A. V., Swanson, C. L., Troy, S., Strauch, P., Pelanda, R., Torres, R. M. (2008) TLR agonists promote marginal zone B cell activation and facilitate Tdependent IgM responses. J Immunol 180, 3882-8.

57. Cinamon, G., Zachariah, M. A., Lam, O. M., Foss, F. W., Jr., Cyster, J. G. (2008) Follicular shuttling of marginal zone B cells facilitates antigen transport. Nat Immunol 9, 54-62.

58. Hwang, I. Y., Park, C., Harrison, K., Kehrl, J. H. (2009) TLR4 signaling augments B lymphocyte migration and overcomes the restriction that limits access to germinal center dark zones. J Exp Med 206, 2641-57. 
59. Barrio, L., Saez de Guinoa, J., Carrasco, Y. R. (2013) TLR4 signaling shapes B cell dynamics via MyD88-dependent pathways and Rac GTPases. J Immunol 191, 3867-75.

60. Harris, T. H., Banigan, E. J., Christian, D. A., Konradt, C., Tait Wojno, E. D., Norose, K., Wilson, E. H., John, B., Weninger, W., Luster, A. D., Liu, A. J., Hunter, C. A. (2012) Generalized Levy walks and the role of chemokines in migration of effector CD8+ T cells. Nature 486, 545-8.

61. Banon-Rodriguez, I., Saez de Guinoa, J., Bernardini, A., Ragazzini, C., Fernandez, E., Carrasco, Y. R., Jones, G. E., Wandosell, F., Anton, I. M. (2013) WIP regulates persistence of cell migration and ruffle formation in both mesenchymal and amoeboid modes of motility. PLoS One 8, e70364.

62. Freeman, S. A., Jaumouille, V., Choi, K., Hsu, B. E., Wong, H. S., Abraham, L., Graves, M. L., Coombs, D., Roskelley, C. D., Das, R., Grinstein, S., Gold, M. R. (2015) Toll-like receptor ligands sensitize B-cell receptor signalling by reducing actin-dependent spatial confinement of the receptor. Nat Commun 6, 6168 .

63. Schweighoffer, E., Nys, J., Vanes, L., Smithers, N., Tybulewicz, V. L. J. (2017) TLR4 signals in B lymphocytes are transduced via the B cell antigen receptor and SYK. J Exp Med 214, 1269-1280.

64. Conley, M. E., Dobbs, A. K., Farmer, D. M., Kilic, S., Paris, K., Grigoriadou, S., Coustan-Smith, E., Howard, V., Campana, D. (2009) Primary B cell immunodeficiencies: comparisons and contrasts. Annu Rev Immunol 27, 199227.

65. Mortaz, E., Tabarsi, P., Mansouri, D., Khosravi, A., Garssen, J., Velayati, A., Adcock, I. M. (2016) Cancers Related to Immunodeficiencies: Update and Perspectives. Front Immunol 7, 365.

66. Lopez-Granados, E., Perez de Diego, R., Ferreira Cerdan, A., Fontan Casariego, G., Garcia Rodriguez, M. C. (2005) A genotype-phenotype correlation study in a group of 54 patients with X-linked agammaglobulinemia. J Allergy Clin Immunol 116, 690-7.

67. Broides, A., Yang, W., Conley, M. E. (2006) Genotype/phenotype correlations in X-linked agammaglobulinemia. Clinical immunology 118, 195-200.

68. Janssen, W. J., Geluk, H. C., Boes, M. (2016) F-actin remodeling defects as revealed in primary immunodeficiency disorders. Clinical immunology 164, 3442.

69. Moulding, D. A., Record, J., Malinova, D., Thrasher, A. J. (2013) Actin cytoskeletal defects in immunodeficiency. Immunol Rev 256, 282-99.

70. Dobbs, K., Dominguez Conde, C., Zhang, S. Y., Parolini, S., Audry, M., Chou, J., Haapaniemi, E., Keles, S., Bilic, I., Okada, S., Massaad, M. J., Rounioja, S., Alwahadneh, A. M., Serwas, N. K., Capuder, K., Ciftci, E., Felgentreff, K., Ohsumi, T. K., Pedergnana, V., Boisson, B., Haskologlu, S., Ensari, A., Schuster, M., Moretta, A., Itan, Y., Patrizi, O., Rozenberg, F., Lebon, P., Saarela, J., Knip, M., Petrovski, S., Goldstein, D. B., Parrott, R. E., Savas, B., Schambach, A., Tabellini, G., Bock, C., Chatila, T. A., Comeau, A. M., Geha, R. S., Abel, L., Buckley, R. H., Ikinciogullari, A., Al-Herz, W., Helminen, M., Dogu, F., Casanova, J. L., Boztug, K., Notarangelo, L. D. (2015) Inherited DOCK2 Deficiency in Patients with Early-Onset Invasive Infections. N Engl J Med 372, 2409-22.

71. Ochs, H. D. and Thrasher, A. J. (2006) The Wiskott-Aldrich syndrome. J Allergy Clin Immunol 117, 725-38; quiz 739. 
72. Lanzi, G., Moratto, D., Vairo, D., Masneri, S., Delmonte, O., Paganini, T., Parolini, S., Tabellini, G., Mazza, C., Savoldi, G., Montin, D., Martino, S., Tovo, P., Pessach, I. M., Massaad, M. J., Ramesh, N., Porta, F., Plebani, A., Notarangelo, L. D., Geha, R. S., Giliani, S. (2012) A novel primary human immunodeficiency due to deficiency in the WASP-interacting protein WIP. J Exp Med 209, 29-34.

73. Salzer, E., Cagdas, D., Hons, M., Mace, E. M., Garncarz, W., Petronczki, O. Y., Platzer, R., Pfajfer, L., Bilic, I., Ban, S. A., Willmann, K. L., Mukherjee, M., Supper, V., Hsu, H. T., Banerjee, P. P., Sinha, P., McClanahan, F., Zlabinger, G. J., Pickl, W. F., Gribben, J. G., Stockinger, H., Bennett, K. L., Huppa, J. B., Dupre, L., Sanal, O., Jager, U., Sixt, M., Tezcan, I., Orange, J. S., Boztug, K. (2016) RASGRP1 deficiency causes immunodeficiency with impaired cytoskeletal dynamics. Nat Immunol. 


\section{Figure Legends}

Figure 1. Molecular cues involved in B cell dynamics regulation at the follicle. (Right panel) Scheme that summarizes the molecular signals affecting B cell behaviour within the follicle at the initial phase of the humoral immune response (antigen searching and recognition). Once B cells enter to the lymphoid tissue, CXCL13 mediates B cell entrance to the follicle and B cell motility within it, signaling through CXCR5 (light blue-B cell). The lipid chemoattractant $7 \alpha, 25-\mathrm{HC}$ and its receptor EBI2 promote migration towards the interfollicular and outer follicular areas, facilitating B cell scanning of stromal cells at those locations; CXCL13 aids B cells to go back to the inner follicle. The presence of innate stimuli, such as LPS, can stimulate B cells and modify their pattern of motility (increased directionaly, Lévy walks), enhancing their migratory response to CXCL13; by those mechanisms, TLR4 signaling improves B cell ability for seeking antigen. When no antigen is encountered, B cells will exit the follicle and the lymphoid tissue sensing a S1P lipid chemoattractant gradient through the S1PR1, and travel to another lymphoid tissue for continuing the antigen search. If B cells find antigen at the follicular stromal cell network and the BCR signaling is above a certain threshold, they will stop motility and establish the IS (dark blue-B cell), facilitating antigen acquisition; in case the antigen abundancy is not enough to trigger IS formation, B cells will keep moving while integrating BCR signals (kinapse stage; blue-B cell). It is unknow if B cells internalize antigen in the kinapse stage. (Left panel) Cropped image of the follicle showing the location of the subcapsular sinus macrophages and follicular dendritic cells (FDC), both APCs for B cells. Fibroblastic reticular cells (FRC), less abundant in follicles than in the paracortex (T-cell zone), embraced the lymphatic reticular conduits that go across the follicle. 


\section{Figure 2. Molecular cascade involved in halting motile B cells to establish the IS.}

Model summarizing the molecular events that lead to stop motile B cells and establish the IS after BCR recognition of antigen. Motile B cells scan the follicular stromal cell network seeking for antigen; that is mainly mediated by CXCL13/CXCR5, aided by adhesion molecules (LFA-1/ICAM-1) to facilitate B cell close-contact with the stromal cell surface. The recognition of antigen thorugh the BCR triggers Syk activation, which leads to Btk recruitment to the plasma membrane and activation (step 1). Btk brings PIP5KI from the cytosol to the plasma membrane together with it; PIP5KI produces a local increase in $\mathrm{PIP}_{2}$ levels at the B cell:APC contact early during IS formation (first two minutes) (step 2). Local PIP $_{2}$ accumulation mediates the recruiment of vinculin and WASP, involved in adhesion platform assembly and actin polymerization, respectively (step 3). LFA-1/ICAM-1 segregate to the periphery of the B cell:APC contact site, while $\mathrm{BCR} /$ antigen clusters accumulate at the center, defining the pSMAC and cSMAC domains of the mature IS. Vinculin links the cortical F-actin ring with the adhesion molecules at the plasma membrane through its binding to talin and actin, giving stability to the adhesion platform (step 4). Non-muscle myosin-II (NM-II) activity is required to keep vinculin at the pSMAC; NM-II inhibition promotes vinculin dissociation, and pSMAC dissassembly (step 4). While BCR signaling continues, the IS maintains its structure and B cells are stopped (step 5). Antigen consumption at the APC surface might attenuate or finish BCR signaling, and thus drive the synapse to take apart and regain cell motility in response to CXCL13 (step 6). The B cell internalized antigen while at the IS stage; acquired antigen is degraded and presented as antigenic peptides in the context of MHC class-II molecules at the B cell surface. 

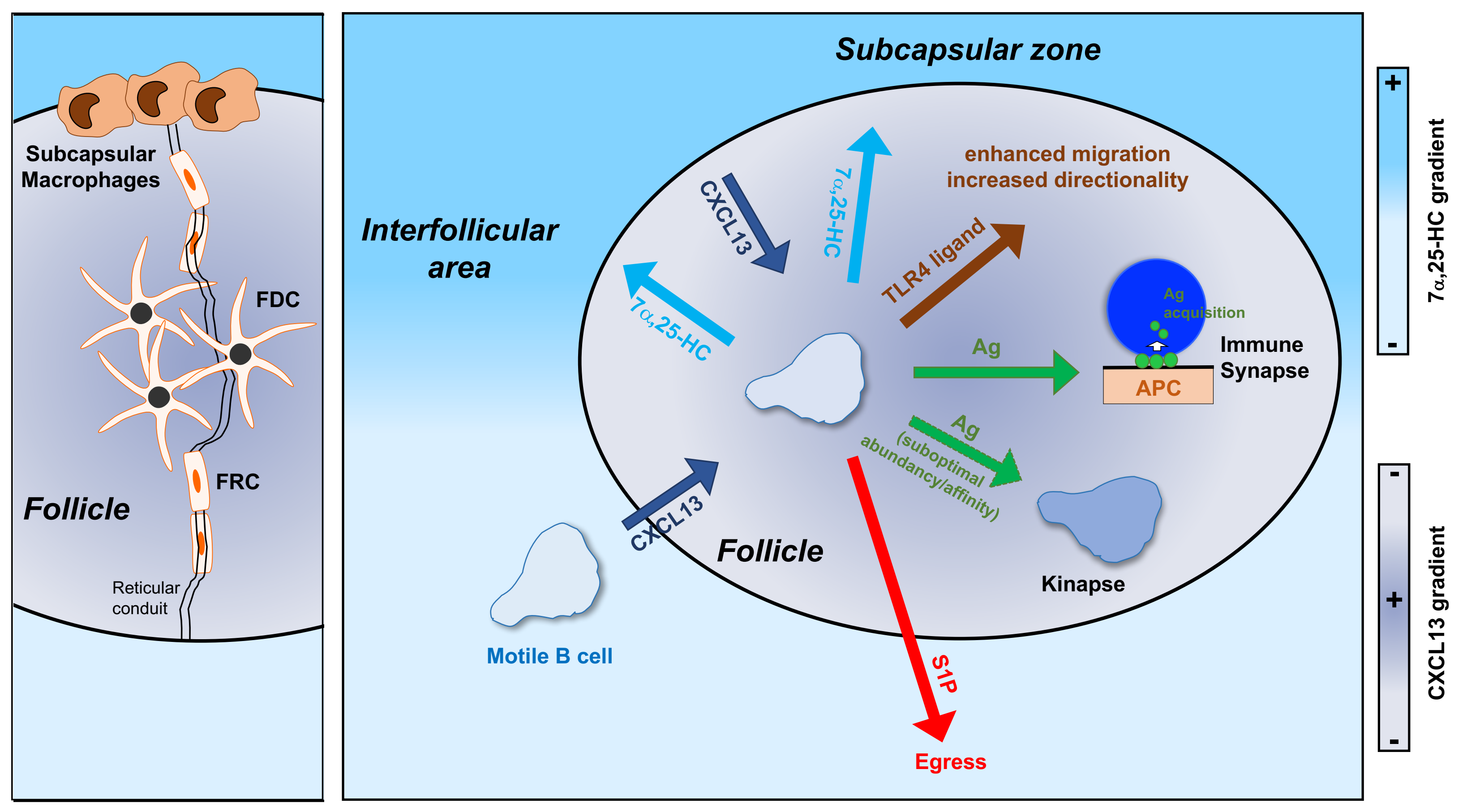

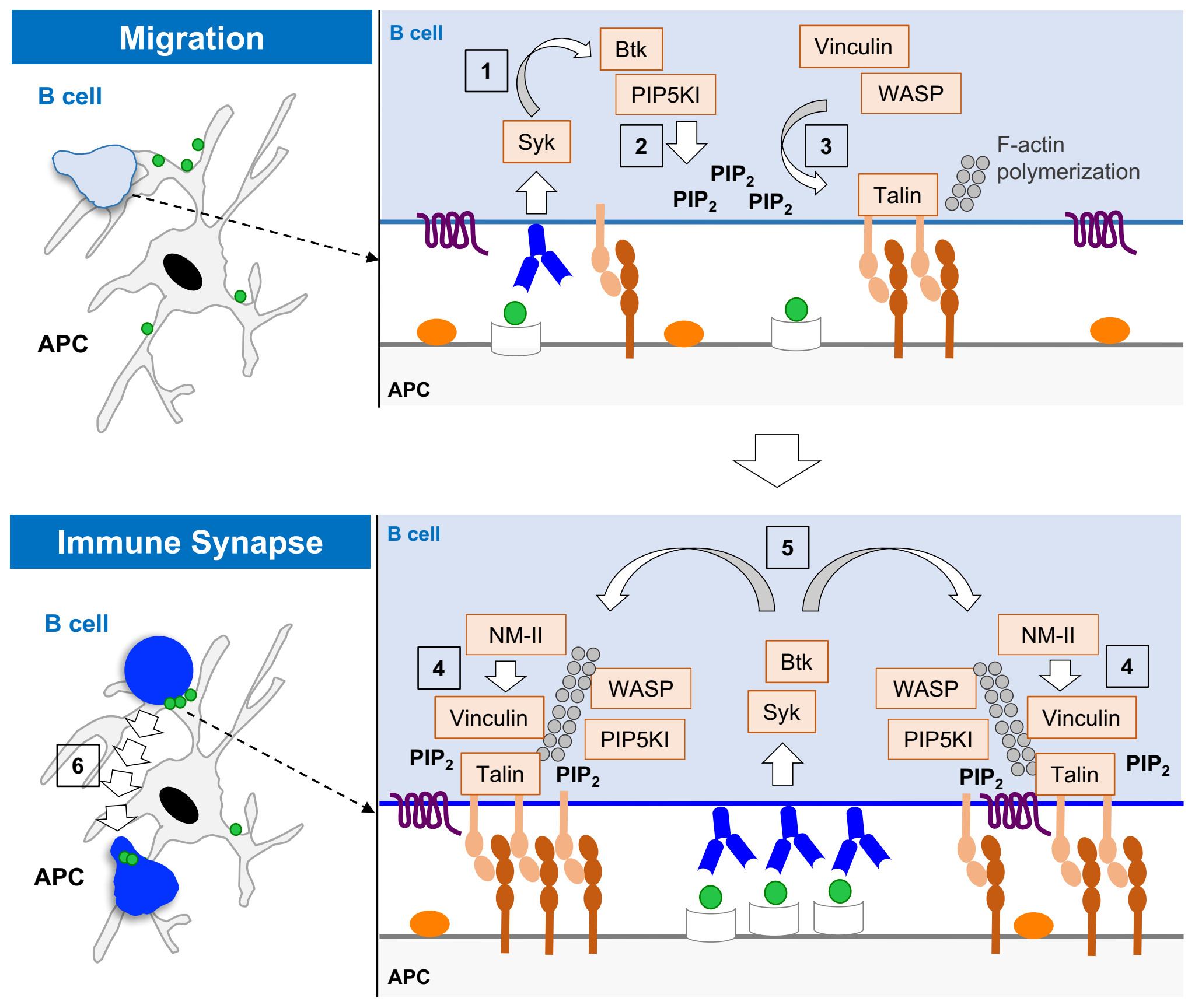